\title{
Community Influences on Schooling and Work Activity of Youth in Pakistan
}

\author{
VALERIE L. DURRANT
}

INTRODUCTION

The schooling and work activities of youth remain fundamental to their human capital development. Yet we have limited understanding of factors influencing these activities in Pakistan and elsewhere. The bulk of research on children's work and schooling looks primarily to household-level factors to explain current rates. As such, activities' of youth are viewed as a product of family strategies for confronting poverty. On the other hand, the influences at the community level on work and schooling of youth have received relatively little attention and remain largely undeveloped in the literature. Further, work and schooling activities remain are usually investigated separately in the analyses. Most studies focus on either the work activities or schooling of youth, despite recent appeals to examine these activities simultaneously [DeGraff, Bilsborrow and Herrin (1993); Mahmood, Javaid and Baig (1994) and Weiner and Noman (1997)].

The purpose of this paper is to assess the participation of youth in work and schooling activities and the way household and community factors shape these activities. I address two central research questions in this paper. First, what is the distribution of Pakistani youth in work and schooling activities? Second, what factors influence the likelihood that youth engage in work and/or schooling? Particularly, what is the influence of community-level factors (specifically, availability of schools, wage returns to education, and infrastructure development) on the activities of youth?

\section{LITERATURE REVIEW}

\section{Youths' Education in Pakistan}

A number of studies have investigated factors affecting children's attendance, retention, and performance in school. Of particular importance are characteristics of

Valerie L. Durrant is a Berelson Fellow with the Population Council, Islamabad.

Author's Note: Due to space limitations, an abridged version of the original paper is offered here. The full-length paper is available from the author on request. The author gratefully acknowledges Sonalde Desai for comments on an earlier draft. 
households and parents that impede or facilitate school attendance. The argument advanced follows Becker's (1965) quality-quantity trade-off theory. Children residing in households with more financial resources (indicated by higher incomes, expenditures, and/or parents' education) are more likely to attend and complete school than those with fewer resources. Likewise, children from large households are seen as competing for resources, and thus as less likely to attend and complete school.

In addition to age, gender, and region of residence of the youth, the socioeconomic status of the household, education of the parents, and household structure are important determinants of children's enrolment in school. The inverted-U relationship between school attendance and age and negative effects of being female, from a poor family, and rural on children's schooling in Pakistan are well-documented [see Burney and Irfan (1991); FBS (1998); Khan (1993) and Sathar and Lloyd (1993)]. Additionally, parental demand for education, usually measured with mother's and father's educational attainment levels correlates highly with the school enrolment and attainment of children, particularly in the case of the influence of mother's education on the school attendance and completion of girls [Sathar and Lloyd (1993)].

A common approach to explanations of children's education in Pakistan focuses on the relative influence of the supply versus demand of schools [FBS (1998); Gazdar (1999) and Sathar and Lloyd (1993)]. The central question is whether socioeconomic conditions and strategies of households or the availability and accessibility of quality schools better predict a child's school attendance. Research does suggest that the availability of schools, particularly public, same-sex schools for girls, is fundamental to school attendance [FBS (1999); Gazdar (1999); Sathar and Lloyd (1993); Weiner and Noman (1997)], though the importance of supply of schools has been called into question by some studies [Burney and Irfan (1991) and FBS (1998)].

\section{Youths' Work in Pakistan}

Child labour in developing countries is viewed as a household strategy for poor families and those stretching their resources over a large number of members, largely following Becker (1965). Youths' work is thus seen to result from the same variables influencing their education, but in the inverse. As such, household structure, parental characteristics, and household socioeconomic status emerge as central determinants of work. Early research investigating the causes of child labour supports that household structure (the number, age, and sex of members in the household) and household socioeconomic status (measured with income, parental education levels, and landholdings) are reliable indicators of whether children participate in paid labour or not [DeTray (1984); Rosenzweig and Evenson (1977) and Rosensweig (1978)]. 
However, the problem of measuring children's work has weakened studies focusing on Pakistan and is further hampered by the isolation of a single activity performed by children [Mahmood, Javaid and Baig (1994)]. Models include a series of variables that capture household factors and community factors like wage structures and demand for labour [Mahmood, Javaid and Baig (1994) and Hamid (1994)].

\section{Children's Time Use}

A significant advance occurs with a shift in attention from children's work to children's time use [DeGraff, Bilsborrow and Herrin (1993); Skoufias (1993) and Skoufias (1994)]. Focusing on children's time use in both work and schooling, these studies use more inclusive definitions of children's work and demonstrate the interrelationships between children's work and schooling. Thus, they demonstrate more work by girls, more work by children in middle and upper classes, and specify more complex family processes that occur in allocating household members' time.

\section{Theoretical Framework}

The argument I advance in this paper is that institutional and structural conditions at the community-level work in conjunction with individual and household level characteristics in determining the distribution of youths' activity in schooling and work. I draw on two main theoretical bases to support this argument-specifically, household economics theory and the theoretical work of Mahmood, Javaid, and Baig (1994), aptly justifying the joint analysis of youths' activities, particularly in the case of Pakistan.

First, research on work activities of various family members (including children) using a household economic model [Becker (1965)] demonstrates the importance of examining work activities within the household context [see, for example, DeTray (1984); Evenson (1978); Rosenzweig and Evenson (1977) and Rosenzweig (1978)]. This paper builds on the notion that decisions regarding the use of youths' time occur within a household unit. Because activities of household members influence the situation of other members and the household as a whole, understanding youths' actions requires attention to household structure and the social and economic situation of the families in which children reside.

I also argue that youths' work and schooling activities emerge from the same decision-making processes as advanced in the literature by Mahmood, Javaid, and Baig (1994) and on children's time use. As work and schooling activities of youth are products of the same decision-making processes through which the time of various household members is allocated, focusing on the factors that affect youths' work and those that affect their education are best considered simultaneously. I assume that youth are more likely to be primarily engaged in some purposeful 
activity (namely, work or schooling in this case) than leisure (or the lack of activity). I utilise a categorical, dependent variable that includes various combinations of activity in work and schooling and multinomial logit regression techniques to model youths' work and schooling. The model is summarised by $Y_{i j}=\beta^{\prime}+\varepsilon i j$ where the $i$ th individual makes choice $j$ (category of the independent variable). With four possible outcomes, the model for youths' work and school participation is: Prob $\left(Y_{i}=j\right)$ $=\frac{e^{\beta^{\prime} j^{\prime} x i}}{\sum_{0}^{3} e^{\beta k x i}}$. I argue that three community-level factors are particularly important in conditioning youths' work and schooling participation: the availability of schools, wage returns to education, and infrastructure development. I thus posit the following hypotheses to be tested in the remainder of this paper.

1. Youth living in areas with proximate schools are more likely to be in school and less likely to work than youth living in areas without proximate schools.

2. In areas where labour market characteristics favour schooling, or where returns to education are high), youth are more likely to be in school and less likely to work.

3. Youth who live in areas with better-developed infrastructures (availability of water in the household, electricity and natural gas connections in the local area, and paved roads) are more likely to attend school and less likely to work than youth who live in areas with poor infrastructure capacities.

\section{DATA AND METHODS}

The findings in this paper are based on 1991 PIHS data collected by the Federal Bureau of Statistics and World Bank. The survey data utilise a stratified random sampling design to generate nationally-representative data of households. The 1991 PIHS data are well-suited to the research questions as they involved an extensive line of questioning with which to assess the work status (in paid and unpaid capacities) of individuals age 10 and over.

\section{Sample}

PIHS data include a national sample of 4,711 households from 300 primary sampling units (PSUs). ${ }^{1}$ The sample used in this paper includes 2,838 boys and 2,659 girls aged 10 to $16^{2}$ from 2,704 households. I include all youth in each

${ }^{1}$ PSUs represent villages or communities and contain approximately 200 to 300 households.

${ }^{2}$ Data on work activities are only available for individuals aged 10 and above. I limit the maximum age of youth to 16 to limit the number of individuals in the sample who are married and may exhibit different work and schooling patterns than unmarried individuals. The sample includes 14 boys and 68 girls who are married. 
household to maximise the number and types of youth represented, but adjust for the bias in standard errors introduced by over-representation of large households using the Huber-White procedure [Huber (1967) and White (1980)]. The sample includes those with non-missing values on all variables includes (87 percent of the original sample). Most excluded observations have missing values on the dependent variable. Differences of means test demonstrate few significant differences (results available from author on request).

\section{Dependent Variable}

Central to the analysis is a categorical dependent variable including various combinations of youths' participation in work and schooling. I investigate four possible discrete outcomes of youths' time use: (1) school attendance but not work participation, (2) participation in work ${ }^{3}$ and no school attendance, (3) participation in work and school attendance, and (4) neither school attendance nor work. Constructed in this way, the dependent variable and methods used allow for looking at simultaneous and concurrent decisions influencing school and work as well as investigating the factors that relate to various outcomes.

\section{Independent Variables}

The central independent variables under analysis are school availability, labour market characteristics, and community development. Independent variables (and control variables) are grouped into five categories: (1) school characteristics, (2) labour market characteristics, (3) infrastructure characteristics, (4) child characteristics, and (5) family characteristics, with 4 and 5 representing control variables. A summary of variable definitions is presented in Table 1 and the means and standard deviations are presented separately for urban and rural areas in Table 2.

\section{School Characteristics}

Four categories of school availability are used in this study: (1) a same-sex public school corresponding to the gender of the respondent within 1 kilometre of the PSU, (2) a same-sex private school (but no same-sex public school) within 1 kilometre of the PSU, (3) only a coed school (public or private) within 1 kilometre of the PSU, and (4) no schools within 1 kilometre of the PSU. Because same-sex schools are generally preferred by parents over coed schools in Pakistan to maintain the possibility of female seclusion, and public schools are often more affordable and accessible than private schools, setting up this variable as ordinal represents the availability of schools in terms of the preference and viability for most youth in Pakistan.

${ }^{3}$ To be coded as working (including paid or unpaid work) a youth must spend a minimum of 10 hours per week engaged in these activities. I assume that less than 10 hours of work per week is negligible in its effect on the relationships under investigation and thus coded as not working. 
Table 1

Definitions of Key Variables Used in Multivariate Analysis

\begin{tabular}{|c|c|}
\hline Variable & Definition \\
\hline Age & Age in years \\
\hline Adult Males Present & \# of males over age 16 present in household \\
\hline Adult Females Present & \# of females over age 16 present in household \\
\hline Adolescent Males Present & \# of males aged 10 to 16 present in the household \\
\hline Adolescent Females Present & \# of females aged 10 to 16 present in the household \\
\hline Children $<10$ & \# of children under age 10 present in the household \\
\hline Household Per Capita Consumption & Log of total HH expenditures divided by household size \\
\hline Mother Literate & Respondent's mother can write a letter (yes=1) \\
\hline Father Literate & Respondent's father can write a letter (yes=1) \\
\hline Household Owns Land & $\begin{array}{l}\text { Household owns agricultural land or land used for a business } \\
\text { (yes=1) }\end{array}$ \\
\hline Household Owns Business & Household owns a family business (yes=1) \\
\hline Household Owns Livestock & Household owns at least 1 sheep, goats, or cows (yes $=1$ ) \\
\hline Province & Punjab, Sindh, Balochistan, NWFP (Punjab omitted) \\
\hline \multirow{2}{*}{\multicolumn{2}{|c|}{$\begin{array}{l}\text { School Availability (No School } \\
\text { within } 1 \text { Kilometre of PSU Omitted) }\end{array}$}} \\
\hline & \\
\hline Same-sex Public School & $\begin{array}{l}\text { Same-sex public school available within } 1 \text { kilometre of village. } \\
\text { For boys, includes all-boy schools. For girls, includes all-girl } \\
\text { schools. (yes=1) }\end{array}$ \\
\hline Private School & $\begin{array}{l}\text { Same-sex private school available (but no same-sex public) within } \\
1 \text { kilometre of village. For boys, includes all-boy schools and coed } \\
\text { schools. For girls, includes only all-girl schools. (yes=1) }\end{array}$ \\
\hline Coed School & Only school available within 1 kilometre of PSU is a coed school. \\
\hline Negative Returns to Education & $\begin{array}{l}\text { Ratio of mean wage for illiterate adults in PSU to the mean wage } \\
\text { for literate adults in PSU }<1 \text { (yes=1) }\end{array}$ \\
\hline $\begin{array}{l}\text { Small, Positive Returns to } \\
\text { Education }\end{array}$ & $\begin{array}{l}\text { Ratio of mean wage for literate adults in PSU to mean wage for } \\
\text { literate adults is between } 1 \text { and } 2 \text { (yes=1) }\end{array}$ \\
\hline Large, Positive Returns (Omitted) & $\begin{array}{l}\text { Ratio of mean wage for literate adults in PSU to mean wage for } \\
\text { literate adults }>2 \text { (yes }=1 \text { ) }\end{array}$ \\
\hline Electricity/Natural Gas & $\begin{array}{l}\text { No households in PSU have electric (rural) or natural gas (urban) } \\
\text { connections (yes=1) }\end{array}$ \\
\hline Household Water Source & Main water source for village is within households (yes=1) \\
\hline Unpaved Roads & Main roads in PSU are unpaved (yes=1) \\
\hline Work & $\begin{array}{l}\text { Respondent worked at least } 10 \text { hours in paid or unpaid (agricultural } \\
\text { labour or work in family business) during the past } 7 \text { days (yes=1) }\end{array}$ \\
\hline School & Respondent reports currently attending school (yes=1) \\
\hline \multicolumn{2}{|l|}{ Dependent Variable } \\
\hline School only & School=yes, Work=yes \\
\hline School and Work & School=yes, Work=no \\
\hline Work only & School=no, Work=yes \\
\hline Neither & School=no, Work=no \\
\hline
\end{tabular}


Table 2

Means and Standard Deviations of Independent Variables for Youth in Pakistan, PIHS 1991

\begin{tabular}{|c|c|c|c|c|c|}
\hline \multirow[b]{2}{*}{ Variable } & \multicolumn{2}{|c|}{ Urban } & \multicolumn{2}{|c|}{ Rural } & \multirow{2}{*}{$\begin{array}{c}\text { Urban-rural } \\
T \text {-test }\end{array}$} \\
\hline & Mean & Std. & Mean & Std. & \\
\hline$\overline{\text { Age }}$ & 12.87 & 2.02 & 12.83 & 2.03 & 0.8236 \\
\hline Gender & 0.49 & 0.5 & 0.47 & 0.5 & 1.2533 \\
\hline Adult Males in $\mathrm{HH}$ & 2.18 & 1.33 & 2.21 & 1.43 & -.8124 \\
\hline Adult Females in $\mathrm{HH}$ & 1.89 & 1.14 & 2.02 & 1.26 & $-3.8265 * * *$ \\
\hline Adolescent Males in $\mathrm{HH}$ & 0.88 & 0.9 & 0.84 & 0.91 & 1.5161 \\
\hline Adolescent Females in $\mathrm{HH}$ & 0.86 & 0.9 & 0.8 & 0.92 & $2.599 * *$ \\
\hline Children $<10$ in $\mathrm{HH}$ & 2.45 & 1.95 & 3.03 & 2.5 & $-9.5798 * * *$ \\
\hline HH Per Capital Expend. (Logged) & 6.26 & 0.65 & 6.01 & 0.57 & $15.5607 * * *$ \\
\hline Mother Literate & 0.21 & 0.41 & 0.04 & 0.19 & $20.6168 * * *$ \\
\hline Father Literate & 0.54 & 0.5 & 0.34 & 0.47 & $14.6969 * * *$ \\
\hline HH Owns Land & 0.07 & 0.26 & 0.43 & 0.49 & $-32.893 * * *$ \\
\hline HH Owns Family Business & 0.48 & 0.5 & 0.27 & 0.45 & $15.9698 * * *$ \\
\hline HH Owns Livestock & 0.16 & 0.37 & 0.77 & 0.42 & $-.573296 * * *$ \\
\hline Punjab & 0.48 & 0.5 & 0.52 & 0.5 & $-2.6881^{* *}$ \\
\hline Sindh & 0.29 & 0.46 & 0.25 & 0.43 & $3.4652 * * *$ \\
\hline Balochistan & 0.07 & 0.25 & 0.05 & 0.23 & $2.1568 *$ \\
\hline NWFP & 0.16 & 0.36 & 0.18 & 0.38 & -1.9088 \\
\hline No School W/in 1 Kilometre & 0.06 & 0.24 & 0.1 & 0.3 & -4.9089 \\
\hline Same-sex Public School W/in 1 Kil. & 0.73 & 0.45 & 0.82 & 0.38 & $-8.2652 * * *$ \\
\hline Same-sex Priv. School W/in 1 Kil. & 0.12 & 0.33 & 0.02 & 0.15 & $14.3415^{* * *}$ \\
\hline Coed School W/in 1 Kilometre & 0.09 & 0.29 & 0.06 & 0.24 & $4.3613^{* * *}$ \\
\hline Neg. Returns to Education & 0.41 & 0.49 & 0.51 & 0.5 & $-7.2378 * * *$ \\
\hline Small, Pos. Returns to Education & 0.31 & 0.46 & 0.28 & 0.45 & $2.4141^{*}$ \\
\hline Large, Pos. Returns to Education & 0.28 & 0.45 & 0.21 & 0.41 & $5.8133^{* * *}$ \\
\hline PSU has no Nat. Gas Connections & 0.46 & 0.5 & 1 & na & na \\
\hline PSU has no Electric Connections & 0 & na & 0.08 & 0.28 & na \\
\hline Water in Household & 0.8 & 0.4 & 0.24 & 0.43 & $49.8355^{* * *}$ \\
\hline PSU has Unpaved Roads & 0.22 & 0.41 & 0.31 & 0.46 & $-7.5925^{* * *}$ \\
\hline$N$ & 2838 & & 2659 & & 5497 \\
\hline
\end{tabular}

Source: PIHS, 1991.

$n a=$ not available due to lack of variability in variable for rural or urban region. $* p>.05, * * p>.01, * * * p>.001$.

\section{Labour Market Characteristics}

While previous studies have focused on wage levels of men, women, and children to indicate returns to employment and competition with schooling, I use returns to education within local labour markets to avoid problems of endogeneity with child wage levels. I measure returns to education using a ratio measure. Specifically, returns to education are measured by taking the mean wages for literate 4 adults in the PSU over the mean wages for illiterate adults in the PSU. From this I

${ }^{4}$ Respondents who reported being able to write a letter are considered literate. 
create an ordinal-level variable to be used in the analysis including categories for negative returns to education (a ratio under 1); small, positive returns to education (ratio between 1 and 2); and large, positive returns to education (ratio over 2).

\section{Infrastructure Characteristics}

The level of development in a community influences labour needs of the family, primarily in the area of unpaid labour. The accessibility of energy in the community is measured using questions from the community questionnaire about the percentage of households in the community connected to electrical power and the percentage of households in the community with natural gas connections. Specifically, I construct a dummy variable indicating whether any household in the PSU has a natural gas connection and whether any household in the PSU has access to electricity in order to capture the infrastructure in the community as opposed to the household's socioeconomic status. It should be noted that all urban communities have access to electricity while no rural communities have access to natural gas. Both variables are included in the model to capture variability within urban and rural regions in addition to between them. The interpretation of results associated with the availability of natural gas and electricity should take into account this limitation.

To measure whether a community's water source is primarily at the household level, I utilise a question from the community questionnaire requesting the most commonly used sources of drinking water for residents in the PSU. A respondent is coded as living in an PSU with a household-level water supply if the community representative responded that the primary source of water to households in the PSU was piped to houses or collected in household tanks (yes=1). All other sources of water (i.e., handpumps, wells, rivers) are coded as not having household-level water sources.

The final measure of a community's development level is the construction material of the main roads in the PSU. I include a dummy variable indicating whether the major roads in the PSU are unpaved (unpaved=1, paved=0).

\section{Control Variables}

Characteristics of the youth and the household are incorporated mainly as control variables. The individual factors included are age and gender of the youth. Two categories of household characteristics are included: those related to the household structure and those indicating the socioeconomic position and resources of the household. Finally, month of interview is included to capture variation by season. Refer to Table 1 for definitions and measurement of these variables. 


\section{RESULTS}

The participation of Pakistani boys and girls in work and schooling activities is presented in Table 3. The importance of looking at youths' work and schooling simultaneously is apparent in looking at the distribution of Pakistani youth over the four combinations of these activities presented. While 54.2 percent of youth are enrolled in school with no significant work responsibilities and 14.4 percent are engaged in work activity (6.6 percent in paid work and 7.8 percent in unpaid capacities), roughly 3 percent participate in both work and schooling. More importantly, 28.5 percent of youth neither participate in schooling nor work.

As is clear from Table 3, youths' participation in work and schooling varies greatly by gender and region. Boys are more likely than girls and urban youth are more likely than rural youth to attend school—both exclusively and in combination with work. 71 percent of urban boys and 59 percent of rural boys compared to 58 percent of urban girls and 26 percent of rural girls are only attending school. Boys are also more likely to engage in work than are girls in both urban and rural areas. In urban areas, 14 percent of boys are working (9.2 percent in paid work and 4.4 percent in unpaid work) compared to only 4 percent of girls (3 percent in paid work and 1 percent in unpaid work). The difference is smaller for youth in rural areas where 22 percent of boys work (7 percent in paid work and 15 percent in unpaid work) compared to 18 percent of girls ( 7 percent in paid work and 11 percent in unpaid capacities).

Table 3

Distribution of Children Aged 10-16 Across Categories of Work and Schooling by Region and Gender, Pakistan, 1991

\begin{tabular}{lccccc}
\hline & $n$ & School Only & School and Work & Work Only & Neither \\
\hline Boys & 2,838 & 65.2 & 4.8 & 17.8 & 12.2 \\
Urban & 1,442 & 71.4 & 2.4 & 13.6 & 12.6 \\
Rural & 1,396 & 58.7 & 7.3 & 22.1 & 11.9 \\
Girls & 2,659 & 42.4 & .9 & 10.9 & 45.8 \\
Urban & 1,396 & 57.5 & 1.2 & 4.3 & 37.1 \\
Rural & 1,263 & 25.7 & .6 & 18.1 & 55.5 \\
All Urban & 2,838 & 64.6 & 1.8 & 9.0 & 24.6 \\
All Rural & 2,659 & 43.1 & 4.1 & 20.3 & 32.6 \\
Total & 5,497 & 54.2 & 2.9 & 14.4 & 28.5 \\
\hline Source: PIHS, 1991, author's calculations. & & & &
\end{tabular}


Due to sample size considerations, I combine paid and unpaid work for the multivariate analysis, though it should be noted that girls and boys demonstrate distinctively different patterns of paid and unpaid work participation. Boys are more likely to combine work and schooling than are girls in both urban and rural areas, but particularly so for rural areas. Finally, girls are roughly 3 times as likely to fall into the "neither" category (neither attending school nor working) as boys in urban areas and almost 5 times as likely in rural areas. Clearly, this category must be interpreted carefully as it captures many girls who have significant housework responsibilities, which is not included in the definition of work used in this paper.

The multinomial logit relative risk ratios for all combinations of work and schooling are presented in Table 4. The first model includes control variablesindividual and household level characteristics. Model 2 includes control variables and community-level factors. I first discuss the results in model 1 , and then turn to those in model 2.

\section{Gender}

Boys are roughly three times more likely than girls to combine work with schooling as opposed to solely attending school. They are also slightly less likely than girls to participate in work only (78 percent) as opposed to school only. Finally, boys are only about $1 / 7$ as likely as girls to be engaged in neither work nor schooling as opposed to school only.

\section{Region}

Urban youth are also significantly more likely to attend school only and less likely to engage in work than their rural counterparts. Specifically, youth residing in urban areas are only 59 percent as likely to engage in work only and 72 percent as likely to participate in neither work nor schooling as opposed to solely attending school as youth residing in rural areas, controlling for other individual and household-level variables in the model. Urban and rural youth do not demonstrate significant differences in their work participation as opposed to activities other than school only.

\section{Age}

As age increases, the likelihood that work will be combined with school as opposed to just attending school increases 1.4 times with each year of age. The same pattern is also exhibited with regard to the likelihood of working and not attending school. Pakistani youth are 1.5 times more likely to engage solely in work activity as opposed to solely attending school with each additional year of age. Similarly, each additional year of age increases the likelihood that youth engage in neither work nor schooling by 1.3 as opposed to solely attending school. Finally, older youth are 
Table 4 
Table 4 
Table 4 
slightly more likely to work only as opposed to combining work and school than younger youth and slightly less likely to engage in neither activity as opposed to working.

\section{Household Structure}

Five variables included in the model to capture household structure. Only the family structure variables reflecting the presence of adults in the household have significant effects on youths' work and schooling activity controlling for other variables in the model. Higher numbers of adults (both male and female) reduce the likelihood that youth work as opposed to just attending school. Each additional adult male present in the household significantly decreases the likelihood that youth combine work and schooling or only work as opposed to just attending school. Finally, each additional adolescent male decreases the likelihood that work will be combined with schooling, given that the youth is not solely attending school by about 23 percent. The number of adolescent females and number of children under the age of 10 have no significant effects on youths' participation in work and schooling. It should be noted that the relatively small effects of family structure may be caused in part by the per capita expenditure measure in the model as some of the effects of household structure may be contained in the expenditures variable.

\section{Socio-economic Status of the Household}

Increases in a family's socioeconomic status, as indicated by per capita household expenditures and parents' literacy, significantly decrease youths' participation in work only and their lack of participation in either work or schooling. Each unit increase in logged per capita household expenditures decreases the likelihood that a youth engages in work by roughly one half as opposed to solely attending school. Further, each additional unit of logged per capita household expenditures decreases the likelihood of neither working nor attending school as opposed to solely attending school by 50 percent.

Per capita expenditures seem to influence the activities of youth by decreasing the likelihood that they attend school rather than by increasing the likelihood that they work. The relative risk ratios show that the likelihood of working or engaging in neither work nor schooling as opposed to either attending school only or combining work and schooling decreases as per capita expenditures increase. The effects of father's literacy seem to operate in the same manner.

While both mother's and father's literacy decrease the likelihood that youth engage in work only or participate in neither activity as opposed to solely attending school, having a literate mother reduces the likelihood of each more than having a literate father. Further, while both mother's and father's literacy reduce the likelihood that youth will work and go to school, only mother's literacy is 
significant—reducing the likelihood of work and schooling as opposed to solely attending school by almost half.

\section{Ownership of Land, Business, and Livestock}

Household ownership of land, a family business, and livestock are included (as separate variables) to represent factors increasing the demand for labour inside the household. This does seem to be the case. All three variables are associated with higher a likelihood that youth will combine work and schooling as opposed to solely attending school (although ownership of land and a family business are only marginally significant). There are differences among the three however. Clearly, owning livestock has the greatest effect on the distribution of youths' activities. Youth living in households with livestock are roughly 4 times more likely to combine work and schooling and almost twice as likely to work only as opposed to just attending school than youth in households without livestock, controlling for other variables.

\section{Province}

Youth living in Sindh are twice as likely those living in Punjab to combine work and schooling and engage in work activity as opposed to attending school only. Youth in Balochistan, Sindh, and NWFP are significantly more likely than youth in Punjab to engage in neither work nor schooling as opposed to solely attending school.

\section{Effects of Institutional/Community Variables}

The results for the model including the community-level variables are presented in Table 4, model 2. The magnitude and significance of individual and household factors remain almost the same when included the measures of school availability, returns to education, and infrastructure development in a community with a few critical exceptions.

The first noticeable difference between model 1 and model 2 among the control variables occurs with the variable for gender. In model 1 , the results indicate that boys are significantly less likely than girls to participate in work only as opposed to just attending school. In model 2, the direction of this relationship remains the same, but the significance level associated with the lower likelihood of boys to work than girls falls to a marginal level of statistical significance (with $p<.08$ ) when community-level variables are included in the model. Thus, the differences of boys and girls work participation may be accounted for by differences in community-level factors including school availability, returns to education, and infrastructure development. 
The urban-rural differences in youths' work participation and in youths' participation in neither work nor schooling also lose their significance when community-level variables are included in the model. While urban youth appear to be slightly less likely than their rural counterparts to combine work and schooling, only work, or participate in neither activity (indicating that they are attending school more than rural children) in model 2, none of these differences are statistically significant. Controlling for individual, household, and community variables in the model, there are no significant differences between urban and rural youth in their participation in work and schooling.

However, in model 1, before the variables accounting for community structure are included, urban/rural region of residence is significant in influencing the participation of youth in various combinations of work and schooling. Thus, critical differences between urban and rural areas exist that structure youths' involvement in work and school beyond those at the household and individual levels. The effect of living in an urban or rural area on youths' school participation is conditioned largely by differences in institutional and structural provisions. In other words, urban youth are more likely to attend school and less likely to work than rural youth because of community characteristics rather than differences in household structure or family resource levels.

A small change occurs in the household structure variables when communitylevel variables are included in the model. The negative effect of each additional adult female present in the household in increasing the likelihood that a youth works as opposed to just attending school in model 1 loses its significance at the $p<.05$ level when community-level variables are included in the model (as in model 2). Because women (and children) are the primary performers of household duties in Pakistan, including structural variables like water and power availability in the community may decrease the significance of an independent measure for adult women on youth's work and schooling.

The final two differences in the control variables between model 1 and model 2 occur with the ownership of land and livestock. When controlling for community level variables, the ownership of land achieves statistical significance at the .05 level. A similar shift occurs in the effect of livestock ownership on youths' participation in neither work nor schooling as opposed to attending school only. In model 1, youth in households with livestock are more likely to participate in neither work nor schooling as opposed to just attending school as youth living in households without livestock. After including community-level variables, the difference in the likelihood that youth will fall in the "neither" category as opposed to just attending school between children in households with livestock and those in households without is not statistically significant. 


\section{Availability of Schools}

The data support that the availability of a same-sex school significantly decreases the likelihood that youth work as opposed to solely attending school. Youth living in PSUs having a same-sex public school within 1 kilometre are only 55 percent as likely as those living in areas with no schools to be working as opposed to solely attending school, controlling for other variables in the model. Additionally, they are 71 percent as likely to be engaged neither in work nor schooling as opposed to attending school only than those without any proximate schools (though this is only significant at the .053 level). Thus, the data support the hypotheses that youth with same-sex public schools in or near their PSU are more likely to attend school and less likely to work. The availability of same-sex private schools and coed schools within a kilometre do not have statistically significant effects on youths' work and schooling participation as opposed to school only.

In sum, the availability of proximate schools is an important and statistically significant determinant of youths' work and schooling participation, but only the availability of same-sex public schools makes a difference by decreasing the likelihood of working as opposed to solely attending school. Same-sex private schools may not have significant effects on youths' activities because they are inaccessible to many households, especially in rural areas. Further, because many parents resist sending their youth (both girls and boys) to coed schools to keep boys and girls separate in accordance with female seclusion, it is not surprising that coed schools have no significant effect on the activities of children. Because female seclusion is likely to affect girls' activities more than boys, and the value of and investments into education in Pakistan differ by gender, it is possible that an interaction effect between gender and the availability of coed schools in suppressing the significance of these variables.

\section{Returns to Education}

I hypothesised that youth in areas characterised by negative returns to education or small returns to education would be less likely to be in school, and hence, more likely to work or fall into the "neither" category. The results provide marginal support for this hypothesis. While most of the relative risk ratios are in the predicted direction - that youth in areas with negative returns to education are more likely to participate in activities other than school only-these results fail to achieve statistical significance, with the exception of those in the "neither" category (which is only marginally significant at the .067 level), controlling for all other variables in the model. Further, youth in areas exhibiting small returns to education are 1.7 times more likely to combine work with schooling as opposed to attending school only. However, again, this relationship is statistically significant only at the .092 level. 
These results moderately support that low returns to education reduce incentives youth have in participating in schooling, however, they fail to show that this, in turn, increases youths' propensity to work. What may be happening is that youth who see no monetary benefits to education are less likely to attend school; and youth who see small benefits to schooling are more likely to attempt to combine work with schooling, rather than detaching themselves completely from the educational system. These conclusions should be viewed as tentative given their marginal statistical significance.

\section{Infrastructure Development}

The data fail to support the hypothesis that youth in areas without access to natural gas and electricity in the community would be less likely to attend school and more likely to work. However, youth living in PSUs with the major source of water within the household (as opposed to community pumps, wells, rivers, etc.) are only 64 percent as likely to work as opposed to solely attending school than youth in villages without household water supplies. Further, youth living in PSUs with inhouse water sources are only 51 percent as likely as those in PSUs without household water sources to work only as opposed to combining work and schooling. Together, these results suggest that household water sources increase youths' school attendance directly rather than indirectly by decreasing work participation.

The last community development indicator used in the analysis involves whether the main roads in the village are paved or not. The results suggest that, controlling for other variables in the model, the construction material of an area's roads (specifically, whether or not they are paved) bears no significant effect on a youths' participation in various combinations of work and schooling.

It is possible that the diverse effects of paved roads on youths' work and schooling participation serve to cancel each other out. Paved roads may make transportation to both work and schooling easier. If (ease of) transportation is not an issue, other factors already in the model are likely to determine whether youth are more likely to attend school or work. The lack of significance of this variable may also be due to differences across urban and rural areas.

\section{Model Improvement}

Though the results of the community-level variables are mixed, it is possible that the effects of some of these variables are not statistically significant because they are compounded with other variables in the model and effects are cancelling each other out. Another way to look at the influence of community-level variables on youth work and schooling is by assessing the model improvement between models 1 and 2. The log likelihood for model 1 is -4594.1609 and for model 2 is -4548.1729. The model improvement is thus 93.976 and is statistically significant at 
the .001 level with 9 degrees of freedom. Thus, the community-level variables as a group significantly improve our understanding of youths' work and schooling.

\section{DISCUSSION AND CONCLUSION}

To summarise, youths' participation in work and schooling is conditioned by the community context in which they reside. Overall, youth living in areas with proximate same-sex schools and with household-sources of water are less likely to work and more likely to be in school relative to school only, even when controlling for other individual and household level factors known to influence youths' participation in these activities. The results indicate that while family-decision making processes influence youths' participation in work and schooling as demonstrated by the significant effects of household structure and household socioeconomic status on participation in work and schooling, these processes are structured by institutional factors outside the household.

The importance of community variables on youths' work and schooling activities is apparent not only in the direct effects of these variables on these activities, but also in explaining disparate patterns of participation across rural and urban areas and between boys and girls. Both gender and regional differences in youths' work and schooling activity are accounted for, at least in part, by disparate levels of community resources available in the villages in which youth reside.

The findings in this paper point to several theoretical and policy considerations that are worth noting. This paper contributes to the existing literature in two key ways. First, this work is among the first to explore the relationship between work and schooling simultaneously. While others have looked at the two activities together in the same paper or have merged them by focusing on children's time use, this paper uses multinomial logit techniques to assess the activities concurrently. There are theoretical and practical benefits to doing so. Theoretically, this technique better models to actual decision-making process in which youth and their families participate. Practically, the results provide support for Weiner and Noman's (1997) argument, at least in part, that one way of reducing the work activity of youth is to increase accessibility of schooling.

Second, the results point to the importance of community level factors on household decisions. These results indicate that explanations of youths' work and schooling activity in Pakistan resting solely as a product of the poverty of families are too simplistic. Recognising that the actions of individuals and are shaped in terms of opportunities and barriers in the surrounding community provides avenues by which education can be increased and youths' work expectations lessened without having to intervene in family processes such as provision of same-sex public schools (particularly for girls) and improving water supply to communities. 


\section{REFERENCES}

Becker, Gary S. (1965) A Theory of the Allocation of Time. Economic Journal 75: 493-517.

Burney, Nadeem A., and Mohammed Irfan (1991) Parental Characteristics, Supply of Schools, and Child School Enrolment in Pakistan. The Pakistan Development Review 30:1 21-62.

DeGraff, Deborah S., Richard E. Bilsborrow, and Alejandro N. Herrin (1993) The Implications of High Fertility for Children's Time Use in the Philippines. In C. Lloyd (ed) Fertility, Family Size, and Structure: Consequences for Families and Children. New York: Population Council. 297-329.

DeTray, Dennis (1984) Children's work activities in Malaysia. Population and Development Review 9:3 437-455.

Evenson, Robert E. (1978) Time Allocation in Rural Philippine Households. American Journal of Agricultural Economics 60:2 322-330.

Federal Bureau of Statistics (FBS) (1998) Education Sector Performance in the 1990s: Analysis from the PIHS. Islamabad: Federal Bureau of Statistics.

Gazdar, Haris (1999) Universal Basic Education in Pakistan: A Commentary on Strategy and Results of a Survey. Sustainable Development Policy Institute, Islamabad. (Sustainable Development Policy Institute Working Paper No. 39.)

Hamid, Shahnaz (1994) A Micro Analysis of Urban Child Labour: Some Determinants of Labour and its Conditions. The Pakistan Development Review 33:4 1249-1271.

Huber, P. J. (1967) The Behaviour of Maximum Likelihood Estimates under Nonstandard Conditions. Proceedings of the Fifth Berkeley Symposium on Mathematical Statistics and Probability 1: 221-233.

Khan, Shahrukh R. (1993) South Asia. In E. M. King and M. A. Hill (eds) Women's Education in Developing Countries: Barriers, Benefits, and Policies. Baltimore: John Hopkins University Press. 211-246.

Mahmood, Moazam, Tariq Javaid, and Ajmal Baig (1994) Why Children do not Go to School in Rural Pakistan-Some Estimates and a Theoretical Framework. The Pakistan Development Review 33:4 1231-1245.

Rosenzweig, Mark R., and Robert Evenson (1977) Fertility, Schooling, and the Economic Contribution of Children in Rural India: An Econometric Analysis. Econometrica 45:5 1065-1079.

Rosenzweig, Mark R. (1978) The Value of Children's Time, Family Size and Nonhousehold Child Activities in a Developing Country: Evidence from Household Data. In J. Simon (ed) Research in Population Economics Vol. 1. Greenwich, CT: Jai. 331-347.

Sathar, Zeba, and Cynthia B. Lloyd (1993) Who Gets Primary Schooling in Pakistan: Inequalities among and within Families. The Pakistan Development Review 33:2 103-134. 
Skoufias, Emmanuel (1994) Market Wages, Family Composition and the Time Allocation of Children in Agricultural Households. Journal of Development Studies 30:25 335-360.

Skoufias, Emmanuel (1993) Labour Market Opportunities and Intrafamily Time Allocation in Rural Households in South Asia. Journal of Development Economics 40: 277-310.

Weiner, Myron, and Omar Noman (1997) The Child and the State in India and Pakistan. Karachi: Oxford University Press.

White, H. (1980) A Heteroskedasticity-consistent Covariance Matrix Estimator and A Direct Test for Heteroskedasticity. Econometrica 48: 817-830. 